\title{
Leadership in the Radiology field for teaching staff in Sudan during 2012-2013
}

\author{
Maha Esmeal Ahmed Esmeal ${ }^{1}$, Mwahib Sid Ahmed Mohammed Osman \\ Aldosh $^{2}$ \\ 1 Ph. D, Assistant Professor-Radiological Sciences Department-Applied Medical College, \\ Najran University- Kingdom of Saudi Arabia \\ 2 Ph. D, Assistant Professor, Co-ordinator of Radiological Sciences Department Applied Medical College - \\ Najran University- Kingdom of Saudi Arabia
}

\begin{abstract}
:
The practice of radiology field are undergoing rapid change in the recent years due to technological advanced and the challenges and unique situations presented in higher education settings. Individuals in leadership positions need to have a strong set of leadership skills to affect positive change for radiology educators face many challenges but they have opportunities for trying to improve the quality of radiology education. The objective of this research is to create enough time to teach, to Provide adequate funds for education, to decide exactly what to teach, to Learn how to teach and to develope stable tools for evaluating the quality of teaching. This study performed between January 2012 and October 2013 radiology department teaching staff (20) of Applied Medical College-Radiological Sciences. The study revealed significant results that $93 \%$ of the staff that leader ship affect their work experience in the positive manner, while $7 \%$ of the staff clarified that the leadership role affect their work experience in the negative manner. The leaders that mustsurmount these obstacles in higher education have a different role from faculty of applied medical college - radiological sciences -Sudan universities. Although they may have similar backgrounds in regard to education and lack of preparation for their leadership role. Many leaders may have been high-performing faculty members, but this does not always translate into being strong leaders. It is often assumed that those in leadership positions have the appropriate skills for effective leadership, which requires them to provide guidance and use decisionmaking skills to make the changes that are necessary for success. However, many times leaders have very little administrative experience or training for the role. These leadership skills need to be developed in order for the leader to be successful.

Key words: Leadership Challenges Radiology department Staff Sudan universities
\end{abstract}

\section{Introduction :}

Academic Radiology Departments have three missions : education, research and the delivery of clinical services. Although the leadership of strong academic radiology departments has found ways to harmonize these missions, and most departments continue to adequately educate radiology students. The education mission faces challenges (1). The scientific field of radiology is unique in healthcare because of its design of fusing technology and medicine. In recent years, this scientific merger has become even more pronounced with the use of computer aided detection (CAD) in combination with existing equipment and the trend of hybrid modalities such as PET/CT(positon emission tomography-computed tomography). If technologists find themselves struggling to keep current with the new processes and equipment within the specialty field, how much more challenging is it for the same technologist to then manage these specialties(2).

The objective of this research is to examine the role of leadership and its effect in the work of the staff of Applied Medical College of Radiological Sciences in Sudan and to create enough time to teach, to Provide adequate funds for education, to decide exactly what to teach, to Learn how to teach and to develope stable tools for evaluating the quality of teaching students.

The purpose of this study that the faculty members struggle to be given time to teach because the allocation of adequate time to faculty members to prepare and deliver education is fraught with difficulties. In most instances, faculty members do not generate income during (education time). Another problem is the difficulty in measuring faculty members education time and devising fair metrics for holding faculty members accountable for education time. Faculty members need to be accountable not only for how they spend their time but also for the results of time spent on task in terms of their departments missions. This study performed between January 2012 and august 2013 radiology department teaching staff (20) Radiology department staff who satisfy the study criteria will enroll. Data of the study in this period will collect -through questionnaire. 
The major goal of all levels of education including higher education in medicine and the allied health professions, critical thinking is a highly valued and sought after characteristic. Like other clinical fields, most radiologic technologists are asked to be managers by the recognition of their competence in the field and their reputation for a strong work ethic. Technologists should not let pride push them into management unless they truly want to make a difference in healthcare $(3,4)$. The education curriculum may be viewed simplistically as lists of all the technologies and diseases students may encounter [5]. Indeed, the Accreditation Council for Graduate Medical Education has required that all radiology students programs provide learning opportunities for each radio technologist to acquire (specific knowledge, skills, behaviors, and attitudes of six general competencies (patient care, general medical knowledge, practice-based learning and improvement, interpersonal and communication skills, professionalism, and systems based practice) and assess radio technologist learning of these competencies [6]. Because of the pressure to acquire factual knowledge and the relative ease of accessing that knowledge, Alderson [7] stated that today's young radiologists often end their training with a gap between superb interpretation skills and an ill-defined sense of their place in the field of radiology and in the health care delivery system in general. Sub specialization may thwart students needs to learn the general principles of clinical disciplines [8].

There is clearly a strong need to expand the radiology curriculum beyond pure medical knowledge. Recently, medical curricula have increasingly reflected a belief that students should understand concepts rather than just memorize facts [9]. The interpersonal skills of radio technologist have been shown to be less refined than their patients might wish. There is a need for better training to ensure competence in communication skills [10]. Teaching faculty members must ensure that the experience radio technologist of training continues to transform novice practitioners into radio technologist able to think act and keep their focus on the ultimate goal of providing the best and most appropriate care for patients [11]. This transformative learning process has eight principles: increased autonomy, increased independence, the ability to separate one's feelings and opinions from those of others, the ability to critically and respectfully examine the views of others, the ability to set personal and professional goals, the ability to see how one's actions affect the system in which one works, the ability to balance and choose among conflicting priorities and variable self interests and the ability to acknowledge one's role in constructing one's own reality [11]. An expanded curriculum will include the following topics: personal development, stress management, leadership skills, the business side of medicine informatics (including internet skills), social responsibility (ethics, legal issues, responsibility to the community), service orientation and development of interpersonal skills, and critical-thinking skills [12].

To achieve these goals, the curriculum must be broad based and extend beyond the mere acquisition and use of factual knowledge. This type of curriculum is difficult to justify in the current environment, in which many students perceive that their success in radiology is determined purely by their ability to pass board examinations. A first step toward adopting such a curriculum would be to move the board oral examinations.

\section{Challenges to leadership:}

Education must have a purpose and a mission [13]. Although were Applied Medical CollegeRadiological Sciences once devoted primarily to educating medical students, they have now evolved intocomplex organizations, many of which place greater emphasis on research and clinical businesses than on educating future radio technologist [14]. As the size of faculties has increased, participation in the education of students has become a marginal activity for a large percentage of medical school faculties. Medical education, the singularly distinctive mission of medical schools, has become, in many institutions, somewhat of a byproduct of their principal business lines of research and clinical service delivery [14]. These missions have jumped to the forefront because the clinical enterprise is by far the major source of income for medical schools, and research is seen to garner prestige for schools, as well as income generated from external grant funding.

The principal challenge to academic leaders is staying true to the academic mission, recognizing equal importance for its three components of education, clinical, and research. The education mission is at risk. The core competency of any academic medical department is education, and in technical colleges were the sole purveyors of education. More recently, we have seen a trend whereby these institutions are ceding this competency to others. For example, many large corporations have developed their own internal education programs for their staff members. More affluent corporations even have teaching campuses that in many respects mimic small university campuses. In addition, we are seeing a shift to privatization in the education industry, with the development of many for profit educational businesses [15]. Applied Medical CollegeRadiological Sciences college must rededicate themselves to teaching and regain their dominant role in the purveyance of education. Leadership must face and solve tenure and job security issues. Although tenure has traditionally provided long term job security for faculty members successful in research, alternative methods of providing equivalent job security must be created for faculty members who choose to emphasize teaching. 
There is nothing inherent in the concept of tenure that says faculty members can do what they want when they want. Because education time is relatively difficult to account for, new methods must be developed for measuring faculty members' time and success in their educational endeavors.

Leadership needs to continually strive to elevate the status of education in departments. Large radiology departments may consider creating distinct divisions of education, with clearly identified and empowered vice chairs of education. These individuals should be separate from directors of radio technologist training. Other ideas for elevating the status of education are developing research programs in the delivery of education providing resident electives in education; and giving work recognition awards that give equal weight to teaching, research, and clinical achievements.

\section{Reslults:}

Faculty members struggle to be given time to teach because the allocation of adequate time to faculty members to prepare and deliver education is fraught with difficulties. The study revealed significant results that $93 \%$ of the staff that leader ship affect their work experience in the positive manner, while $7 \%$ of the staff clarified that the leadership role affect their work experience in the negative manner. In most instances, faculty members do not generate income during (education) time. Another problem is the difficulty in measuring faculty members education time and devising fair metrics for holding faculty members accountable for education time. Faculty members need to be accountable not only for how they spend their time but also for the results of time spent on task in terms of their departments missions The principal challenge to academic leaders is staying true to the academic mission, recognizing equal importance for its three components of education, clinical and research. The education mission is at risk. The core competency of any academic radiology department is education, and in technical colleges were the sole purveyors of education. More recently, we have seen a trend whereby these institutions are ceding this competency to others. For example, many large corporations have developed their own internal education programs for their staff members. More affluent corporations even have teaching campuses that in many respects mimic small university campuses. In addition, we are seeing a shift to privatization in the education industry, with the development of many for profit educational businesses

\section{What to teach :}

The education curriculum may be viewed simplistically as lists of all the technologies and diseases students may encounter. The curriculum should be viewed, however, as the collection of knowledge necessary to produce the desired end product a competent radio technologist. We must define the end product to decide what we need to teach, and that is not an easy task. It is difficult to list all the desirable characteristic s of a good radio technologist, more difficult to rank them, and even more difficult to teach some of these attributes. These include the ability to pass especial examinations, possess great clinical knowledge, provide accurate diagnoses, communicate well, have good people skills, become involved in outside affairs, be a good manager, be able to lead. We all probably agree that these are desirable attributes, but each of us will value and rank these attributes differently. This will always leave us debating about the ideal curriculum. Radiology radio technologist frequently feel overburdened and anxious when they reflect on the sheer volume of material that they believe they must master.

\section{Discussion:}

There is clearly a strong need to expand the radiology curriculum beyond pure medical knowledge. Recently, medical curricula have increasingly reflected a belief that students should understand concepts rather than just memorize facts. The interpersonal skills of radio technologist have been shown to be less refined than their patients might wish. There is a need for better training to ensure competence in communication skills. Teaching faculty members must ensure that the experience radio technologist of training continues to transform novice practitioners into radio technologist able to think act and keep their focus on the ultimate goal of providing the best and most appropriate care for patients . This transformative learning process has eight principles: increased autonomy, increased independence, the ability to separate one s feelings and opinions from those of others, the ability to critically and respectfully examine the views of others, the ability to set personal and professional goals, the ability to see how one s actions affect the system in which one works, the ability to balance and choose among conflicting priorities and variable self interests and the ability to acknowledge one s role in constructing one s own reality .

Because faculty members have probably reached the limits of personal autonomy, faculty members' accountability must be increased, and faculty members must be answerable for their time. Although two essential conditions of job security will surely be preserved, academic freedom of speech and economic security, a third condition that has evolved through practice, independence to achieve broad goals without direction, must be changed. 


\section{Conclusion :}

The practice of radiology field are undergoing rapid change in the recent years due to technological advanced and the challenges and unique situations presented in higher education settings .Finally the Radiology educators face many challenges but they have opportunities for trying to improve the quality of radiology education depend on the leadership through their positive manner.

\section{Acknowledgement:}

Researchers would like to extend gratitude to the Dean ship and staff of the College of Medical Radiological Sciences, Najran University also would like to acknowledge all those who directly or indirectly extend support to this research. Having completed this research. The researchers gratefully acknowledges all those who were covered by this work at Sudan universities. Also researcher would like to express appreciations to the field workers who saved no effort or time to complete this work, those who contribute to this work but their names are not mentioned here and researcher won them special gratitude.

May almighty Allah make this research of special benefit to the development of health services all over the world

\section{References:}

[1]. Ludmerer KM. Time to heal: American medical education from the turn of the century to the era of managed care. New York: Oxford University Press; 1999 Future work: faculty time in the 21st century. Change 1995;May/June:22-3

[2]. Watson RT. Rediscovering the medical school. Acad Med 2003;78: 659-65

[3]. Ludmerer KM. Instilling professionalism in medical education. JAMA1999;282:881-2.

[4]. Plater WM. Future work: faculty time in the 21st century. Change 1995;May/June:22-3

[5]. Gunderman RB, Williamson KB, Frank MF, Heitkamp DE, Kipfer HD.Learner-centered education. Radiology 2003;227:15-7.

[6]. Accreditation Council for Graduate Medical Education. Home page.Available at: http://www.acgme.org.

[7]. Alderson PO. Noninterpretive skills for radiology residents. Introduction to series. Am J Roentgenol 1999;173:1451.

[8]. Watson RT. Rediscovering the medical school. Acad Med 2003;78:659-65.

[9]. West DC, Pomeroy JR, Park JK, Gerstenberger EA, Sandoval J. Criticalthinking in graduate medical education: a role for concept mappingassessment. JAMA 2000;284:1105-10.

[10]. Lurie SJ. Raising the passing grade for studies of medical education JAMA 2003;290:1210-12

[11]. Johnson CE. The transformative process of residency education. Acad Med 2000;75:666-9.

[12]. Beall DP. Beyond imaging. Am Coll Radiol 1999;55:13-26. 1999:

[13]. Plater WM. Future work: faculty time in the 21st century. Change 1995;May/June:22-3.

[14]. Watson RT. Rediscovering the medical school. Acad Med 2003;78:659-65.

[15]. Reading, writing and enrichment. The Economist. January 16, 1999:55-6. Cohen et al./Challenges Facing Radiology Educators 687 